\title{
Penetrating Excimer Laser Keratoplasty with vs without the Homburg Cross-Stitch Marker in Inexperienced Surgeons
}

\author{
Shady Suffo \\ Mohammed El Halabi \\ Berthold Seitz (D) \\ Alaa Din Abdin \\ Cristian Munteanu \\ Loay Daas
}

Department of Ophthalmology, Saarland University Medical Center (UKS),

Homburg, Saar, Germany
Correspondence: Mohammed El Halabi Department of Ophthalmology, Saarland University Medical Center, Kirrberger Straße 100, Bldg. 22, Homburg, 6642I, Germany

Tel +491739920686

Email mohammed.elhalabi@uks.eu
Background and Objectives: The Homburg cross-stitch marker, according to Suffo, was developed in 2017 in the Department of Ophthalmology at Saarland University Medical Center. With this instrument, a surgeon can precisely define and mark the points of the first and second continuous cross-stitch sutures, according to Hoffmann. The aim of this retrospective study was to compare the functional outcomes of Hoffmann's double continuous cross-stitch suture in penetrating keratoplasty (PKP) with vs without the Homburg crossstitch marker in inexperienced surgeons.

Methods: A total of 130 eyes from 130 patients with central corneal scars, corneal dystrophies and advanced keratoconus were included. All eyes underwent elective excimer laser-assisted penetrating keratoplasty (excimer laser PKP) with a diameter of $8.0 / 8.1 \mathrm{~mm}$. In 65 eyes each, surgery was performed without (group 1) or with (group 2) the Homburg crossstitch marker. Corrected distance visual acuity, topographic astigmatism, and refractive cylinder were obtained 6 weeks, 10 months post-PKP as well as 6 weeks after the first and after the second suture removal, respectively. The rate of early postoperative single interrupted suture addition was compared between the two groups.

Results: Visual acuity, astigmatism and refractive cylinder values were significantly more favorable in group 2 (with device) compared to group 1 (without device) before and after suture removal. Postoperative single interrupted suture addition was performed in $34.4 \%$ of patients in group 1 compared to $10.6 \%$ in group $2(P=0.001$, Fisher's Exact Test).

Conclusion: The use of the Homburg cross-stitch marker for excimer laser PKP in young cornea specialists results in significantly better visual acuity before and after suture removal, significantly lower astigmatism and cylinder value before suture removal, as well as a reduced necessity of early postoperative single interrupted suture addition.

Keywords: excimer laser-assisted penetrating keratoplasty, Hoffmann cross-stitch suture, Homburg cross-stitch marker, corrected distance visual acuity, astigmatism, refractive cylinder

\section{Introduction}

Deep Anterior Lamellar Keratoplasty (DALK) is the procedure of choice for corneal scars and corneal dystrophies with intact endothelium. However, PKP represents an established method for visual rehabilitation in various pathological changes of the cornea, such as conditions following acute keratoconus, insufficient corneal stromal thickness (as the risk of intraoperative perforation increases), endothelial decompensation with stromal scars due to endothelial corneal dystrophies or postoperative deep 
corneal stromal scars and condition following herpetic keratitis. The aim of corneal transplantation is to achieve clarity of the optical axis with a corneal surface as regular as possible, thus achieving the best possible visual outcome. $^{1-3}$ In 1905, Eduard Zirm performed the first successful homologous PKP in humans. ${ }^{4}$ Since 1986, Naumann and Lang have developed and perfected the technique of non-mechanical trephination with the excimer laser for PKP. ${ }^{1,2,5}$ Especially for keratoconus - the most common indication for PKP in Germany - this "non-contact" technique is a preferred method besides DALK. "1,3 Nonmechanical excimer laser corneal trephination improves both donor and recipient decentration and reduces "vertical tilt" and "horizontal torsion" of the graft in the recipient bed. This results in lower topographic astigmatism and better visual acuity after suture removal. ${ }^{1,2,5,6}$

These results were achieved by applying the double running diagonal cross-stitch suture that was published in 1976 by Professor Friedrich Hoffmann from Berlin ${ }^{7}$ (Figure 1). The performance of this cross-stitch suture is difficult and requires many years of experience. During the long learning curve, a very precise sense of proportion is achieved to ensure homogeneous suture tension in the area of the donor-host junction. In 2017, a new “7”-shaped, handheld, metal instrument was designed in the Department of Ophthalmology at Saarland University Medical Center in Homburg/Saar. ${ }^{8}$ The instrument is available for trephination sizes of $7.5 \mathrm{~mm}, 8.0 \mathrm{~mm}$, and $8.5 \mathrm{~mm}$ from the company

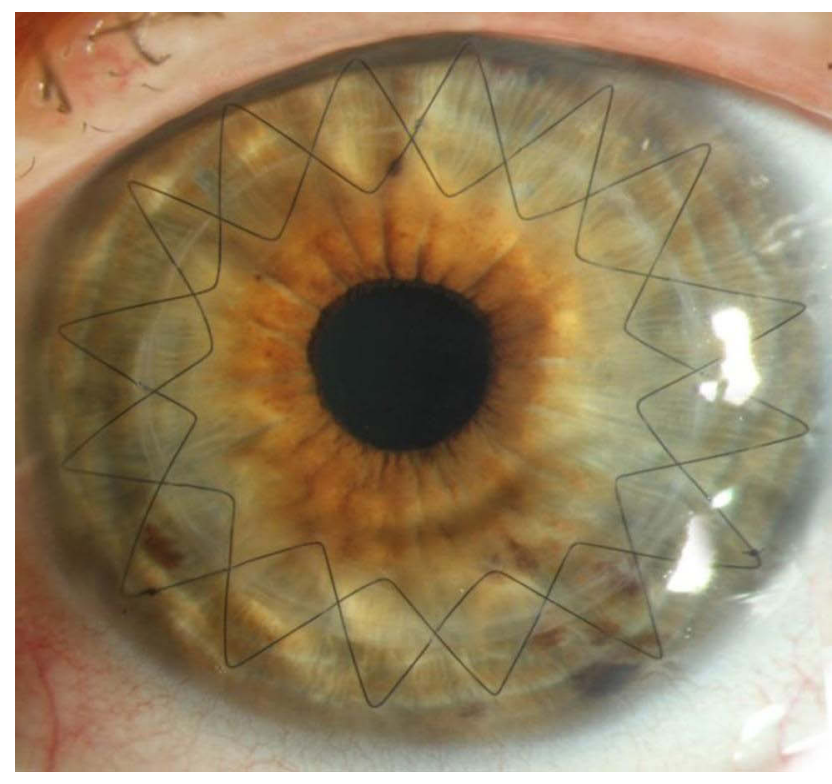

Figure I The double-running diagonal cross-stitch suture according to Hoffmann used in PKP.
Geuder (GEUDER AG, Heidelberg, Germany). This instrument can be used to precisely define the insertion and removal points of the needle for first and second double continuous cross-stitch sutures.

Two tiny prominences on the back surface of the instrument mark these sites on the dry cornea in a punctate manner in both the donor cornea and the host cornea ${ }^{8}$ (Figure $2 \mathrm{~A}$ and B). Therefore, especially the still inexperienced microsurgeon feels very safe when performing the double continuous suture with the new instrument. He/she can thus compensate for his/her non-elaborated and inaccurate sense of proportion, significantly shorten the learning curve, and create a homogeneous continuous suture early on (Figure 3). ${ }^{8,9}$

The aim of this retrospective study was to compare the functional results of Hoffmann's double continuous crossstitch suture in PKP with vs without the Homburg crossstitch marker in inexperienced surgeons.

\section{Patients and Methods}

Between July 2016 and December 2017, 130 elective excimer laser PKP with corneal diameters of 8.0/8.1 mm were performed by inexperienced surgeons at the Department of Ophthalmology at the Saarland University Medical Center. The indications for PKP were:

- Keratoconus $(\mathrm{n}=61)$.

- Central corneal scar in condition after keratitis $(\mathrm{n}=27)$

- Bullous keratopathy in Fuchs' endothelial corneal dystrophy $(\mathrm{n}=17)$

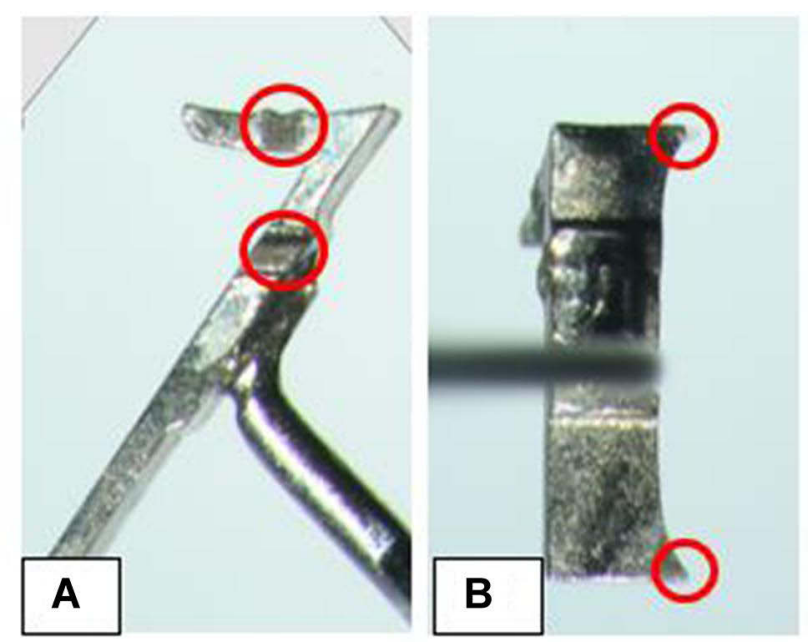

Figure 2 ( $\mathbf{A}$ and $\mathbf{B}$ ) The front surface of the instrument with 2 markings on the long and short arm respectively for positioning the instrument on the cornea (A). The back surface of the instrument: two tiny prominences at both ends of the long arm of the instrument for marking the insertion and removal site of the suture needle after blue staining $(\mathbf{B}){ }^{8}$ 


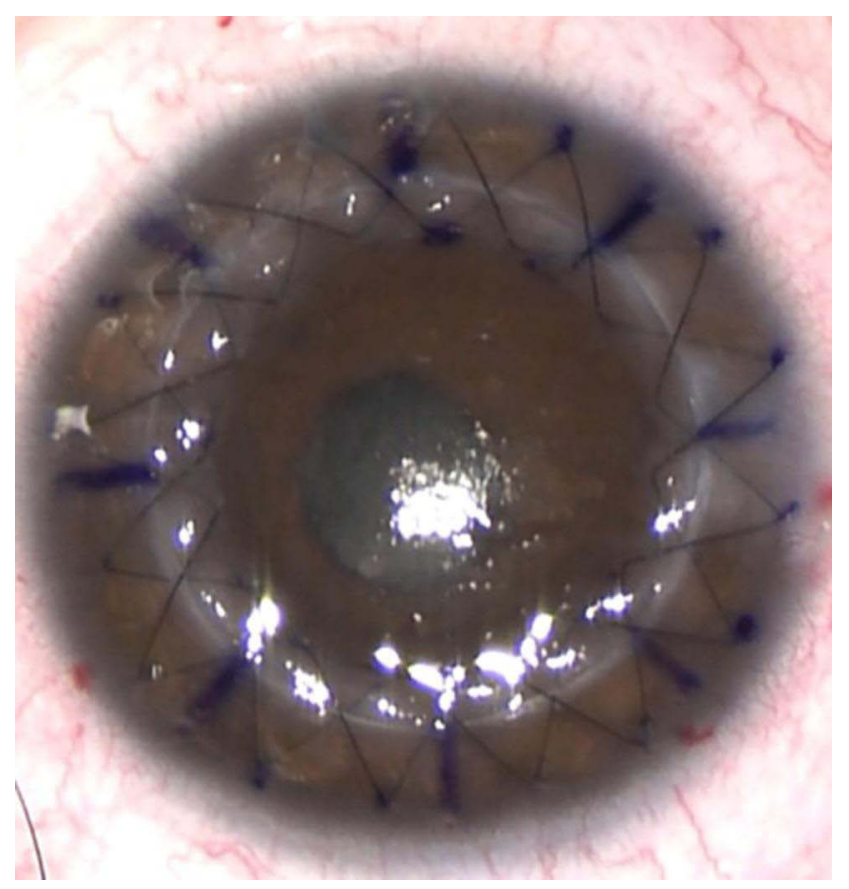

Figure 3 A young surgeon's first independent continuous cross-stitch keratoplasty in a patient using the Homburg cross-stitch marker. The two sutures are crossing almost everywhere over the interface. ${ }^{8}$

- Central corneal scar due to trauma $(n=11)$

- Bullous keratopathy after cataract surgery $(n=7)$

- Stromal corneal dystrophy $(n=4)$

- Granular corneal dystrophy $(n=3)$

Nevertheless in cases of long-standing corneal endothelial decompensation with stromal scarring and high irregular astigmatism with which the patient has never seen well, PKP may be a better option. That is why we have favored PKP in patients with bullous keratopathy and Fuchs' endothelial corneal dystrophy with longstanding endothelial decompensation in 2016.

130 eyes of 130 patients were included in our retrospective study. In this study, we compared between 2 groups. Group 1 consisted of 65 keratoplasties performed without the aid of the Homburg cross-stitch marker. Group 2 consisted of 65 keratoplasties performed with the aid of the Homburg cross-stitch marker. Both groups were operated on by inexperienced surgeons ( 2 surgeons in each group) and all of them performed their first 65 keratoplasties ever.

The basis for comparable results was established by the similarity of the following parameters of both patient groups:

1. All cases were PKP

2. Optical indication for keratoplasty
Table I Distribution of Indications (n) Between the Two Groups. The Differences Between the Indications Were Not Statistically Significant Between the 2 Groups $(P=0.24)$

\begin{tabular}{|l|l|l|l|}
\hline Indications & $\begin{array}{l}\text { Group I } \\
\text { (without } \\
\text { Device) n }\end{array}$ & $\begin{array}{l}\text { Group 2 } \\
\text { (with } \\
\text { Device) n }\end{array}$ & Percent \\
\hline Keratoconus & 24 & 37 & $47 \%$ \\
Scars after keratitis & 17 & 10 & $21 \%$ \\
Fuchs dystrophy & 10 & 7 & $13 \%$ \\
Posttraumatic/ & 10 & 8 & $14 \%$ \\
postsurgical & & 3 & $5 \%$ \\
Corneal dystrophy & 4 & 65 & $100 \%$ \\
Total & 65 & &
\end{tabular}

3. Graft diameter $=8.1 \mathrm{~mm}$, trephine diameter of host cornea $=8.0 \mathrm{~mm}$

4. Central graft

5. Complication-free course of surgery

6. Clear healing of the graft override

7. Age distribution of patients in both groups nearly equal (average of 55 years in both groups)

8. Both groups showed a largely equal distribution of indications $(\mathrm{P}=0.24)$ (Table 1).

9. The suture removal protocol was as follows: The first continued suture removal was performed about 12 months postoperatively and the second consecutive suture removal was performed about 18 months postoperatively.

10. All surgeons in both groups used the manual Placido disc at the end of surgery to adjust the suture.

\section{Main Outcome Measures}

Main outcome measures included corrected distance visual acuity (CDVA) (logMAR) (corrected with glasses), topographic astigmatism, and refractive cylinder (cyl). These values were obtained 6 weeks and 10 months postoperatively in all 130 eyes. In addition, these values were obtained 6 weeks after the first $(n=110)$ and after the second suture removal $(\mathrm{n}=90)$, respectively. The rate of early postoperative single interrupted suture addition was compared between the two groups.

\section{Statistical Procedures}

All statistical analyses were performed with IBM SPSS v27.0.1.0 (Windows). Comparison between groups of continuous variables were performed using the $t$-test (for normally distributed variables) and the Mann Whitney 
$U$-test (for non-normally distributed variables). We also applied the Bonferroni correction for the longitudinal data. To show the association between postoperative resuturing (yes/no) and groups (with/without device), Fisher's Exact Test was used. A p-value less than 0.05 was considered to indicate a statistically significant difference.

\section{Results}

Group 1 showed an increase in mean CDVA from $1.11 \pm$ 0.74 to $0.64 \pm 0.27$ at 6 weeks follow-up postoperatively, to $0.57 \pm 0.40$ at 10 months follow-up postoperatively, to $0.55 \pm 0.42$ at 6 weeks after the first suture removal, and to $0.49 \pm 0.44$ at 6 weeks after the second suture removal.

Group 2 showed an increase in mean CDVA from 1.12 \pm 0.69 to $0.44 \pm 0.27$ at 6 weeks follow-up postoperatively, to $0.32 \pm 0.23$ at 10 months follow-up postoperatively, to $0.31 \pm 0.20$ at 6 weeks after the first suture removal, and to $0.29 \pm 0.22$ at 6 weeks after the second suture removal.

Comparing the two groups, there was statistically significantly better visual acuity $(\mathrm{P}=0.04$, with Bonferroni correction) at 6 weeks, 10 months post operative and 6 weeks after the second suture removal in group 2 compared to group 1 despite the same baseline visual acuity $(\mathrm{P}=0.69)$ (Table 2) (Figure 4).

The mean value of topographic astigmatism in group 1 was $6.95 \pm 3.85 \mathrm{dpt} 6$ weeks postoperatively, $5.50 \pm 3.57$ dpt 10 months postoperatively, $5.45 \pm 3.01 \mathrm{dpt} 6$ weeks after the first suture removal, and $5.32 \pm 3.94 \mathrm{dpt} 6$ weeks after the second suture removal.
Table 2 Corrected Distance Visual Acuity (CDVA) (Mean \pm Standard Deviation) (Min-Max) in the Two Groups at the Different Follow-Up Time Points After PKP. In Group 2 (with Device), The CDVA Was Significantly Better $(P=0.04$, with Bonferroni Correction) Compared to Group I (without Device) at 6 Weeks, 10 Months Post Operative and 6 Weeks After the Second Suture Removal

\begin{tabular}{|c|c|c|c|}
\hline & $\begin{array}{l}\text { Group I } \\
\text { (without } \\
\text { Device) }\end{array}$ & $\begin{array}{c}\text { Group } 2 \\
\text { (with } \\
\text { Device) }\end{array}$ & P-value \\
\hline Preoperative & $\begin{array}{l}1.11 \pm 0.74 \\
(0.30-2.30)\end{array}$ & $\begin{array}{l}1.12 \pm 0.69 \\
(0.22-2.30)\end{array}$ & 0.69 \\
\hline 6 weeks post OP & $\begin{array}{l}0.64 \pm 0.27 \\
(0.22-1.30)\end{array}$ & $\begin{array}{l}0.44 \pm 0.27 \\
(0.00-1.00)\end{array}$ & 0.04 \\
\hline 10 months post OP & $\begin{array}{l}0.57 \pm 0.40 \\
(0.00-1.30)\end{array}$ & $\begin{array}{l}0.32 \pm 0.23 \\
(0.00-1.00)\end{array}$ & 0.04 \\
\hline $\begin{array}{l}6 \text { weeks after Ist } \\
\text { suture removal }\end{array}$ & $\begin{array}{l}0.55 \pm 0.42 \\
(0.10-2.00)\end{array}$ & $\begin{array}{l}0.31 \pm 0.20 \\
(0.00-1.00)\end{array}$ & 0.12 \\
\hline $\begin{array}{l}6 \text { weeks after } 2 \text { nd } \\
\text { suture removal }\end{array}$ & $\begin{array}{l}0.49 \pm 0.44 \\
(0.00-2.00)\end{array}$ & $\begin{array}{l}0.29 \pm 0.22 \\
(0.00-1.00)\end{array}$ & 0.04 \\
\hline
\end{tabular}

In group 2, the mean value of topographic astigmatism was $4.50 \pm 3.65 \mathrm{dpt} 6$ weeks postoperatively, $3.62 \pm 2.27$ dpt 10 months postoperatively, $3.03 \pm 2.45 \mathrm{dpt} 6$ weeks after the first suture removal, and $3.72 \pm 1.94$ dpt 6 weeks after the second suture removal.

Comparing both groups, there was statistically significant lower topographic astigmatism at 6 weeks, 10 months

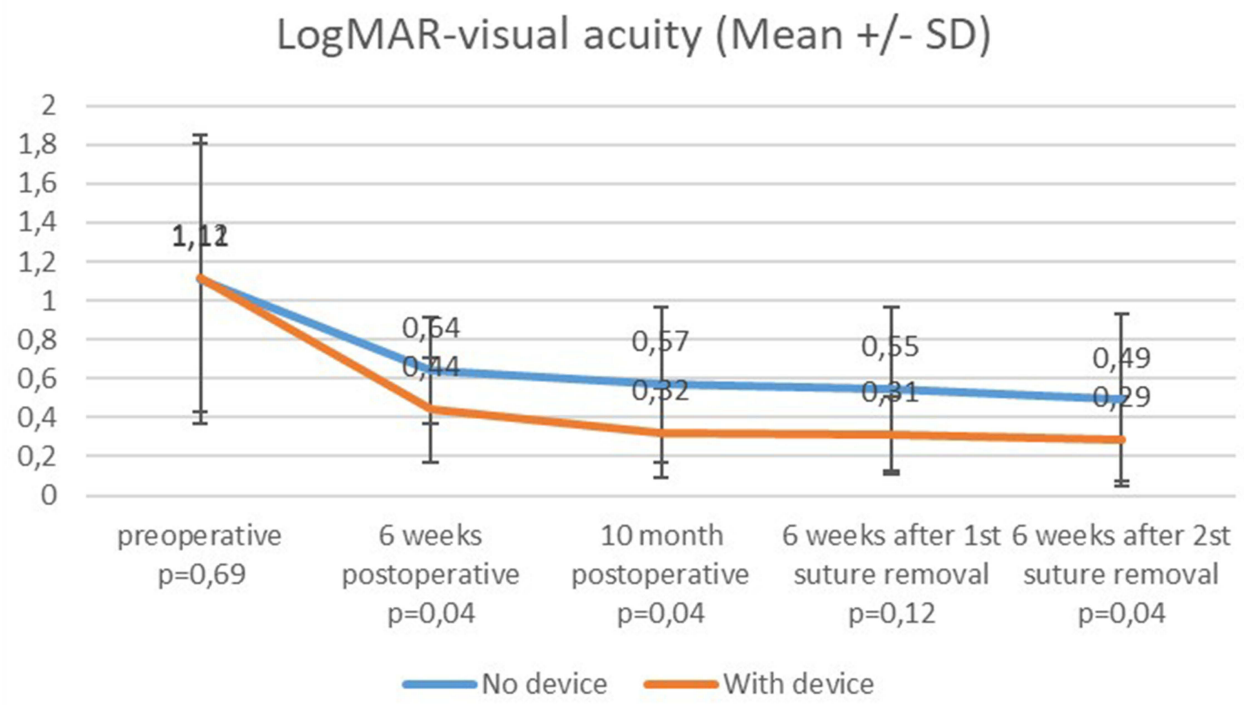

Figure 4 Corrected distance visual acuity (CDVA) (logMAR). There was a statistically significant better visual acuity at 6 weeks, 10 months post operative and 6 weeks after the second suture removal in group 2 (with device) compared to group I (without device). 
Table 3 Topographic Astigmatism (Mean \pm Standard Deviation) (Min-Max) in the Two Groups at Different Time Points After PKP. In Group 2 (with Device), Topographic Astigmatism Was Significantly Lower $(P<0.03$ with Bonferroni Correction) at 6 Weeks, 10 Months Post Operative and 6 Weeks After the First Suture Removal Compared to Group I (without Device)

\begin{tabular}{|l|l|l|l|}
\hline & $\begin{array}{l}\text { Group I } \\
\text { (without } \\
\text { Device) }\end{array}$ & $\begin{array}{l}\text { Group 2 } \\
\text { (with } \\
\text { Device) }\end{array}$ & P-value \\
\hline 6 weeks post OP & $\begin{array}{l}6.95 \pm 3.85 \\
(0.7-20.0)\end{array}$ & $\begin{array}{l}4.50 \pm 3.65 \\
(0.3-16.0)\end{array}$ & 0.002 \\
\hline 10 months post OP & $\begin{array}{l}5.50 \pm 3.57 \\
(0.7-18.0)\end{array}$ & $\begin{array}{l}3.62 \pm 2.27 \\
(0.2-11.9)\end{array}$ & 0.004 \\
\hline 6 weeks after Ist & $\begin{array}{l}5.45 \pm 3.01 \\
(1.0-17.0)\end{array}$ & $\begin{array}{l}3.03 \pm 2.45 \\
(0.9-13.0)\end{array}$ & 0.03 \\
\hline suture removal \\
suture removal
\end{tabular}

post operative and 6 weeks after the first suture removal in group 2 compared to group 1 ( $\mathrm{P} \leq 0.03$ with Bonferroni correction) (Table 3) (Figure 5).

The mean value of the refractive cylinder in group 1 was $6.13 \pm 3.34 \mathrm{dpt} 6$ weeks postoperatively, $4.74 \pm 2.62$ dpt 10 months postoperatively, $5.12 \pm 2.82 \mathrm{dpt} 6$ weeks after the first suture removal, and $4.84 \pm 3.21 \mathrm{dpt} 6$ weeks after the second suture removal.

In group 2, the mean refractive cylinder was $3.78 \pm$ $2.64 \mathrm{dpt} 6$ weeks postoperatively, $3.80 \pm 2.40 \mathrm{dpt} 10$ months postoperatively, $4.06 \pm 2.48 \mathrm{dpt} 6$ weeks after the first suture removal, and $3.51 \pm 1.88 \mathrm{dpt} 6$ weeks after the second suture removal.

Comparing the two groups, there was a statistically significant lower cylinder value at 6 weeks postoperative time point in group 2 compared to group $1(\mathrm{P}=0.002$ with Bonferroni correction) (Table 4) (Figure 6).

Early postoperative single interrupted suture addition due to step formation or a positive Seidel test was performed in 22 of 65 eyes in group 1 (34.4\%), compared with $10.6 \%$ in group 2 ( 7 of 65 eyes) $(\mathrm{P}=0.001$, Fisher's Exact Test).

\section{Discussion}

The visual acuity after successful PKP is largely dependent on graft clarity and postoperative astigmatism. Severe irregular astigmatism is one of the most common causes of patient dissatisfaction after PKP, and can often not be satisfactorily compensated with glasses. ${ }^{1,9,10}$ When performing PKP, every single step, from donor selection, intraoperative trephination and suturing technique to careful postoperative follow-up, can influence the final postoperative refractive outcome. ${ }^{1,2,9,10}$ In order to avoid the feared astigmatism increase after suture removal, a trephine system should be used for PKP that ensures tension-free symmetrical fitting of a circular donor disc into a circular recipient bed with congruent unproblematic watertight adapting incision edges. Currently, these requirements for optimal trephination are most likely to be met by non-mechanical excimer laser

\section{Astigmatism (Mean +/- SD)}

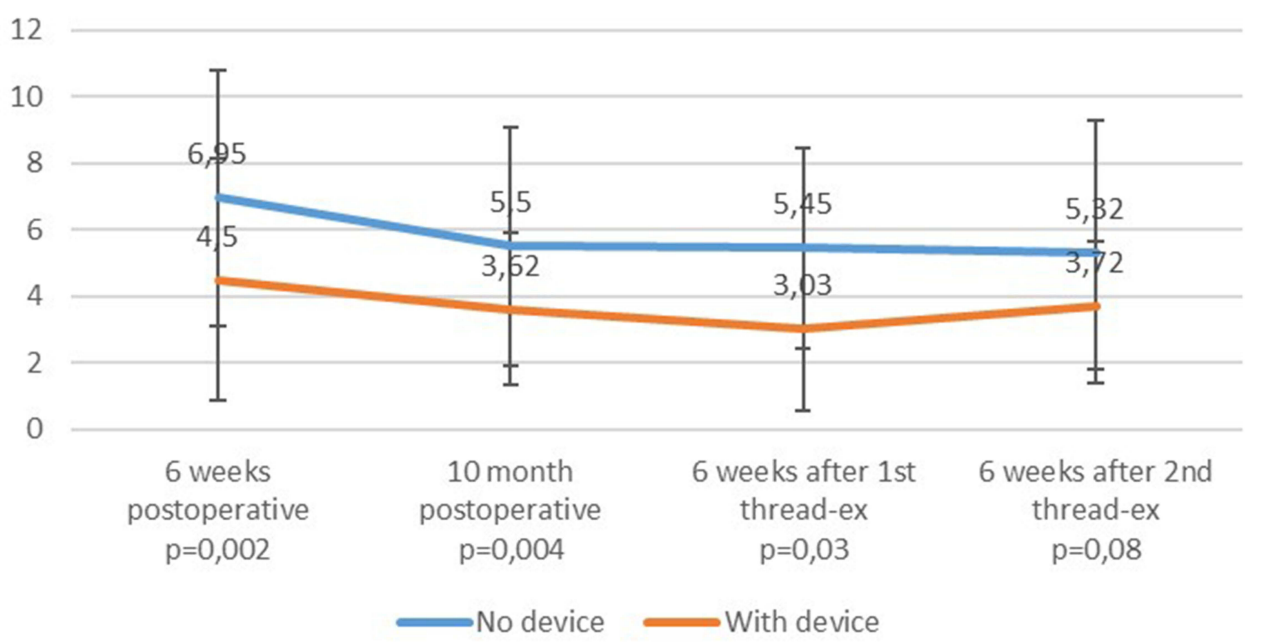

Figure 5 Topographic astigmatism. There was a statistically significant lower topographic astigmatism at 6 weeks, 10 months post operative and 6 weeks after the first suture removal in group 2 (with device) compared to group I (without device). 
Table 4 Refractive Cylinder (Mean \pm Standard Deviation) (MinMax) in the Two Groups at Different Time Points After PKP. In Group 2 (with Device), The Refractive Cylinder Was Significantly Lower ( $P=0.002$ with Bonferroni Correction) at 6 Weeks Postoperative Time Point Compared with Group I (without Device)

\begin{tabular}{|c|c|c|c|}
\hline & $\begin{array}{l}\text { Group I } \\
\text { (without } \\
\text { Device) }\end{array}$ & $\begin{array}{c}\text { Group } 2 \\
\text { (with } \\
\text { Device) }\end{array}$ & P-value \\
\hline 6 weeks post OP & $\begin{array}{l}6.13 \pm 3.34 \\
(0.75-13.0)\end{array}$ & $\begin{array}{l}3.78 \pm 2.64 \\
(0.75-11.0)\end{array}$ & 0.002 \\
\hline 10 months post OP & $\begin{array}{l}4.74 \pm 2.62 \\
(0.75-11.0)\end{array}$ & $\begin{array}{c}3.80 \pm 2.40 \\
(0.25-9.5)\end{array}$ & 0.16 \\
\hline $\begin{array}{l}6 \text { weeks after Ist } \\
\text { suture removal }\end{array}$ & $\begin{array}{l}5.12 \pm 2.82 \\
(1.0-11.25)\end{array}$ & $\begin{array}{l}4.06 \pm 2.48 \\
(0.50-13.0)\end{array}$ & 0.16 \\
\hline $\begin{array}{l}6 \text { weeks after } 2 \text { nd } \\
\text { suture removal }\end{array}$ & $\begin{array}{l}4.84 \pm 3.21 \\
(0.25-12.5)\end{array}$ & $\begin{array}{c}3.51 \pm 1.88 \\
(0.25-8.0)\end{array}$ & 0.12 \\
\hline
\end{tabular}

trephination, which has proven many advantages in terms of topographic astigmatism and visual acuity after suture removal. ${ }^{8,9,11,12}$

In addition, early astigmatism with sutures in place appears to depend strongly on the suture placement technique and the approaches used for intra- and postoperative suture adjustments (the signature of the microsurgeon). ${ }^{13}$ Hjortdal et al reported on the impact of suture regularity on topographic astigmatism after PKP. In this study, they investigated whether suture regularity measured immediately after surgery had an effect on post-PKP astigmatism. As a result, the uniform stitch length at the surface seems to improve the optical quality of the graft after suture removal. ${ }^{14}$

Nowadays, 3 suture techniques are predominantly used: the most common one is the double continuous cross-stitch suture, according to Hoffmann. ${ }^{7}$ Other techniques include the single continuous suture and multiple single sutures. ${ }^{15,16}$ The double continuous suture technique provides an even distribution of suture tension in the wound area, as well as more wound stability. Another advantage of two sutures is that one suture can be removed earlier if it loosens or tears, while the other still provides secured wound stability. ${ }^{16,17}$

In the PKP treatment of low-risk Keratoplasty (eg keratoconus or Fuchs' corneal endothelial dystrophy), the double continuous cross-stitch suture is superior to the single continuous stitch suture due to the reduced risk of suture loosening and lower postoperative topographic astigmatism. However, after suture removal, there are no significant differences in topographic astigmatism. ${ }^{17,18}$

Intraoperatively, a Placido disc can be used to adjust the tightness of the suture to reduce postoperative astigmatism and improve visual acuity. ${ }^{19}$ Few published dates indicate that intraoperative keratometry result in refractive cylinder values that are comparable to those in our group 2 with device. ${ }^{20}$

The suture loosening in the early postoperative period after PKP may result in step formation and increase in postoperative astigmatism. In addition, the risk of

\section{Cylinder value (Mean +/- SD)}

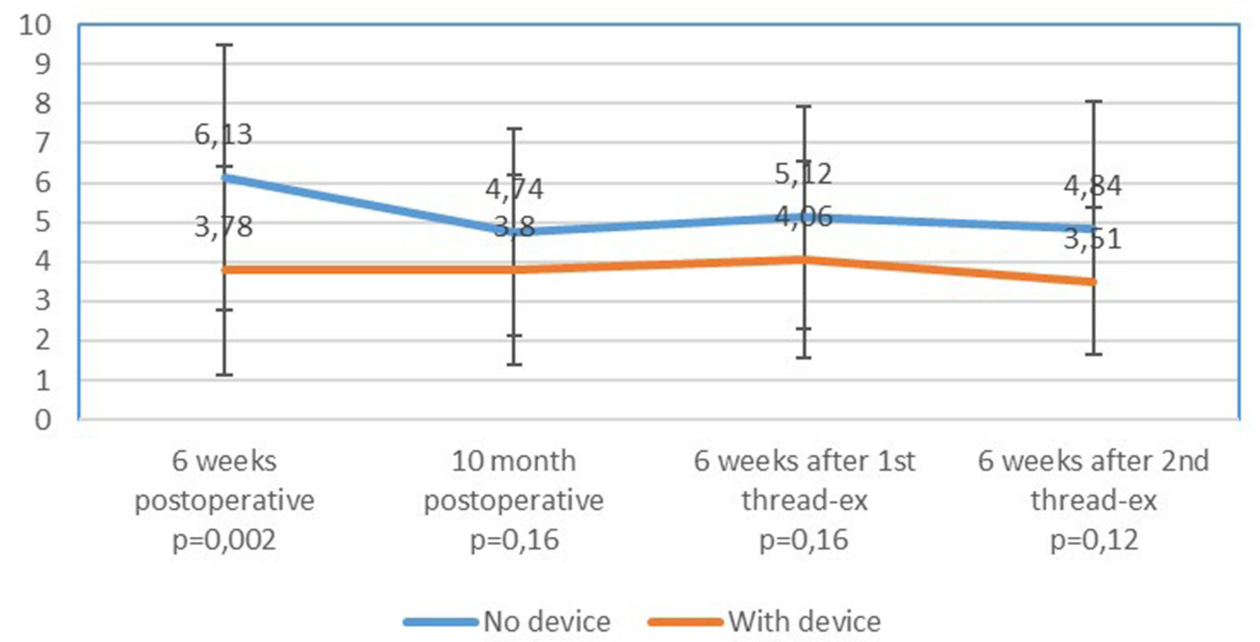

Figure 6 Refractive cylinder. There was a statistically significant lower cylinder value at 6 weeks post operative time point in group 2 (with device) compared to group I (without device). 
immunological graft reactions and infections increases as well. ${ }^{18}$ For this reason, we recommend the fixation of the graft with multiple single sutures in high-risk keratoplasty (eg infectious keratitis).

Nonetheless, it should be considered that multiple single sutures induced higher corneal astigmatism and longer duration of operation compared to the double continuous cross-stitch suture. ${ }^{18}$ Furthermore, the double continuous cross-stitch suture allowed early visual rehabilitation. ${ }^{21-23}$

The double continuous cross-stitch suture according to Hoffmann $^{7}$ is difficult to perform correctly and requires a precise sense of proportion. The success of this suture requires that the tension of the two sutures along the interface be the same throughout so that the graft can be inserted without vertical or horizontal torsion, thus ensuring optimal wound healing. This can only be achieved if the distance between the insertion and removal sites of the needles is the same everywhere so that the two sutures cross in every instance over the interface. $^{24,25}$ This is impossible for the inexperienced surgeon with his/her still untrained eye.

Two decades ago, the Duncker marker has been proposed. ${ }^{26,27}$ This instrument was shaped like an 8-bite star with a cross in the center. To mark the continuous corneal suture, the 8-bite star was to be coloured from below with a blue dye, then stamped onto the dried cornea, thereby drawing often too thick lines on the cornea. ${ }^{27}$ This reduced the intraoperative overview due to dispersing blue dye. As a result, an inexperienced operator could not accurately assess the depth of the stitch, which often caused superficial fixation of the graft. This fact often led to early postoperative suture loosening. Therefore, this marker has never been used widely in the operating room and has been fully abandoned today.

In contrast, the Homburg cross-stitch marker according to Suffo $^{8}$ can be used to solely define the insertion and removal points of the needles for two continuous sutures in an exactly identical manner. The tension of the two sutures will automatically be equally distributed along the $360^{\circ}$ edges of the graft in relationship to the interface and, therefore, the two sutures will cross at each point in the interface without dependence on the surgeon's sense of proportion. ${ }^{8,9}$

The major advantage of Suffo's marker over Dunker's marker lies in its projecting points in contrast to the full lines that are pressed on the surface of the (never fully) dry cornea. Therefore, while using Suffo's marker, the overview remains unaffected. This allows the inexperienced surgeon to perform a very homogeneous continuous cross- stitch suture even during his first PKP and at the same time train his sense of proportion (Figure 3).

This theory was proven in our retrospective study, and the instrument was shown to result in statistically significantly lower astigmatism and cylinder values with better visual acuity both before and after suture removal. The rate of postoperative resuturing was also significantly lower with the aid of the instrument than without it.

\section{Conclusions}

The use of the Homburg cross-stitch marker for excimer laser PKP in young cornea specialists results in significantly better visual acuity before and after suture removal, significantly lower astigmatism at 6 weeks and 10 months postoperatively and 6 weeks after the first suture removal, significantly lower cylinder value at 6 weeks postoperatively, as well as a reduced necessity of early postoperative single interrupted suture addition.

\section{Ethics Statement}

(Investigate the pre-, intra- and postoperative course of elective penetrating keratoplasties performed at Saarland University Eye Hospital during the period 2000-2020.)

This study followed the guidelines of the Helsinki declaration and was approved by the local ethics committee (ID: 13/21) from the Medical Association of Saarland.

According to the Saarland Ethics Committee, an informed consent is not required for retrospective studies. Retrospective data analysis poses no risks to patients. This paper does not include studies in humans or animals.

Information about the storage of the data in pseudonymous form and possible transfer to authorized persons in compliance with the Data Protection Act. The data will be evaluated and published in anonymized form.

\section{Disclosure}

The authors declare no conflicts of interest.

\section{References}

1. Seitz B, Szentmáry N, El-Husseiny M, et al. The penetrating keratoplasty (PKP): a century of success. In: Hjortdal J, editor. Corneal Transplantation. Berlin, Heidelberg: Springer; 2016:67-92.

2. Seitz B, Langenbucher A, Naumann GOH. [The penetrating keratoplasty. A 100-year success story]. Ophthalmologe. 2005;102: 1128-1139. German. doi:10.1007/s00347-005-1291-6

3. Daas L, Hamon L, Ardjomand N, et al. [Excimer laser assisted DALK - A case report from the Homburger Keratoconus Center (HKC)]. Ophthalmologe. 2021. German. doi:10.1007/s00347-021-01342-3

4. Zirm E. [A successful total keratoplasty]. Graefes Arch Clin Exp Ophthalmol. 1906;64:580-593. German. doi:10.1007/BF01949227 
5. Naumann GOH, Seitz B, Lang GK, et al. [193 nm excimer laser trephination in penetrating keratoplasty]. Klin Monbl Augenheilkd. 1993;203:252-261. German. doi:10.1055/s-2008-1045677

6. Seitz B, Langenbucher A, Kus MM, et al. Nonmechanical corneal trephination with the excimer laser improves outcome after penetrating keratoplasty. Ophthalmology. 1999;106:1156-1164. doi:10.1016/ S0161-6420(99)90265-8

7. Hoffmann F. [Suture technique for penetrating keratoplasty]. Klin Monatsbl Augenheilkd. 1976;169:584-590. German.

8. Suffo S, Seitz B, Daas L. The homburg cross-stitch marker for double-running sutures in penetrating keratoplasty. Klin Monatsbl Augenheilkd. 2020;1055:1275-1807.

9. Seitz B, Daas L, Milioti G, Szentmàry N, Langenbucher A, Suffo S. [Excimer laser-assisted penetrating keratoplasty]. Ophthalmologe. 2019;116:1221-1230. German. doi:10.1007/s00347-019-00990-w

10. Naydis I, Klemm M, Hassenstein A, et al. Postkeratoplasty astigmatism: comparison of three suturing techniques. Ophthalmologe. 2011;108:252-259. doi:10.1007/s00347-010-2272-y

11. Seitz B, Hager T, Langenbucher A, Naumann GOH. Re-considering sequential double running suture removal after penetrating keratoplasty - a prospective randomized study comparing excimer laser and motor trephination. Cornea. 2018;37:301-306. doi:10.1097/ICO. 0000000000001420

12. Tóth G, Szentmáry N, Langenbucher A, Akhmedova E, El-Husseiny M, Seitz B. Comparison of excimer laser versus femtosecond laser assisted trephination in penetrating keratoplasty: a Retrospective Study. Adv Ther. 2019;36:3471-3482. doi:10.1007/s12325-019-011 20-3

13. Naumann GOH, Part II. Corneal transplantation in anterior segment diseases. The Bowman Lecture (Number 56) 1994. Eye. 1995;9:395-421. doi:10.1038/eye.1995.98

14. Hjortdal J, Søndergaard A, Fledelius W, Ehlers N. Influence of suture regularity on corneal astigmatism after penetrating keratoplasty. Acta Ophthalmol. 2001;89:412-416a. doi:10.1111/j.1755-3768.2009.017 29.x

15. Filatov V, Steinert RF, Talamo JH. Postkeratoplasty astigmatism with single running suture or interrupted sutures. Am J Ophthalmol. 1993;115:715-721. doi:10.1016/S0002-9394(14)73637-2
16. Dolorico AMT, Tayyani R, Ong HV, Gaster RN. Shortterm and longterm visual and astigmatic results of an opposing 10-0 nylon double running suture technique for penetrating keratoplasty. $J \mathrm{Am}$ Coll Surg. 2003;197:991-999. doi:10.1016/j.jamcollsurg.2003.07.016

17. Jonas JB, Heyer C, Budde WM. Effect of single- and double-running sutures on corneal astigmatism and suture loosening after PKP. $J$ Cataract Refract Surg. 2002;28:1709-1710. doi:10.1016/S08863350(02)01592-4

18. Jonas JB, Budde WM. Loosening of single versus double running sutures in penetrating keratoplasty for keratoconus. Graefes Arch Clin Exp Ophthalmol. 1999;237:522-523. doi:10.1007/s004170050273

19. Robertson I. Optical Control in Keratoplasty. Aust J Ophthalmol. 1974;2:152-153. doi:10.1111/j.1442-9071.1974.tb00220.x

20. Belmont SC, Troutman RC, Buzard KA. Control of astigmatism aided by intraoperative keratometry. Cornea. 1993;12:397-400. doi:10.1097/00003226-199309000-00005

21. Davison JA, Bourne WM. Results of penetrating keratoplasty using a double running suture technique. Arch Ophthalmol. 1981;99:1591-1595. doi:10.1001/archopht.1981.03930020465012

22. McNeill JI, Kaufman HE. A double running suture technique for keratoplasty: earlier visual rehabilitation. Ophthalmic Surg. 1977;8:58-61.

23. Young SR, Olson RJ. Results of a double running suture in penetrating keratoplasty performed in keratoconus patients. Ophthalmic Surg. 1985;16:779-786.

24. Spadea L, Cifariello F, Bianco G, Balestrazzi E. Long-term results of penetrating keratoplasty using a single or double running suture technique. Graefes Arch Clin Exp Ophthalmol. 2002;240:415-419. doi:10.1007/s00417-002-0444-4

25. Kim SJ, Wee WR, Lee JH, Kim MK. The effect of different suturing techniques on astigmatism after penetrating keratoplasty. $J$ Korean Med Sci. 2008;23:1015-1019. doi:10.3346/jkms.2008.23.6.1015

26. Duncker GI, Nölle B. A new cornea-marking device for penetrating keratoplasty and refractive corneal procedures. Ophthalmologica. 1995;209:25-26. doi:10.1159/000310570

27. Duncker GI, Nölle B. [Corneal markers for continuous keratoplasty sutures]. Klin Monbl Augenheilkd. 1995;207:51-52. German. doi:10.1055/s-2008-1035349
Clinical Ophthalmology

\section{Publish your work in this journal}

Clinical Ophthalmology is an international, peer-reviewed journal covering all subspecialties within ophthalmology. Key topics include: Optometry; Visual science; Pharmacology and drug therapy in eye diseases; Basic Sciences; Primary and Secondary eye care; Patient Safety and Quality of Care Improvements. This journal is indexed on PubMed

\section{Dovepress}

Central and CAS, and is the official journal of The Society of Clinical Ophthalmology (SCO). The manuscript management system is completely online and includes a very quick and fair peer-review system, which is all easy to use. Visit http://www.dovepress.com/ testimonials.php to read real quotes from published authors. 